\title{
Selected trace elements concentrations in pregnancy and their possible role - literature review
}

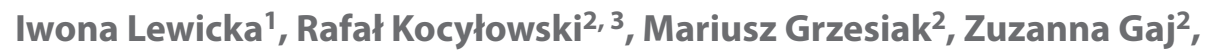 \\ Przemysław Oszukowski ${ }^{2}$, Joanna Suliburska ${ }^{1}$ \\ ${ }^{1}$ Institute of Human Nutrition and Dietetics, Poznan University of Life Sciences, Poznan, Poland \\ 2Department of Perinatology and Gynecology, Polish Mother's Memorial Hospital Research Institute, Lodz, Poland \\ ${ }^{3}$ PreMediCare New Med Medical Centre, Poznan, Poland
}

\begin{abstract}
The aim of this study was to review the role of selected trace elements in pregnancy and fetal development. Citations related to the role of iron ( $\mathrm{Fe})$, zinc $(\mathrm{Zn})$, manganese $(\mathrm{Mn})$, copper $(\mathrm{Cu})$ and selenium $(\mathrm{Se})$ during pregnancy were searched in PubMed, Medline, Web of Science, using keywords and MeSH terms. Inadequate supply of trace elements can cause abnormalities of fetal development and predispose a child to disorders later on in life. Trace elements are the key elements of complex enzymes responsible for the modulation of the antioxidant defense system of the organism. It has been suggested that there is a correlation between reduced levels of trace elements essential for antioxidant function in the body of pregnant women, and an increased risk of developing preeclampsia. Trace elements are components of numerous regulatory enzymes and hormones essential to the division and differentiation of fetal cells and their further development. Mineral deficiencies in pregnant women can cause birth defects of the central nervous system, and growth disorders. Future research should be directed to explain the interaction between trace elements, and establish the optimum levels of macro and micronutrients supplementation, as well as determine the reference values for trace elements in the maternal serum, umbilical cord blood and amniotic fluid.
\end{abstract}

Key words: pregnancy, trace elements, fetal development, preeclampsia, growth disorders, iron, zinc, manganese, copper, selenium

\section{INTRODUCTION}

Ensuring an adequate supply of nutrients, which include trace elements, is particularly important in pregnancy and during lactation. Both deficiency and excess of trace elements in the body can interfere with conception and maintaining a healthy pregnancy, as well as have a negative effect on the development of breast-fed infants.

Trace elements are normally found in the body as a component of metalloproteins and perform a variety of structural and enzymatic functions. They provide a structural component in the skeletal system, teeth, skin, and hair. They are an integral part of myoglobin, hemoglobin, hormones such as Thyroxine and components and activators of enzymes. Trace elements influence fluid and electrolyte balance, regulate acid-base balance and neuromuscular excitability.

Minerals such as zinc, manganese, copper and selenium are key components of complex enzyme systems responsible for antioxidant protection of the organism [1]. This feature seems to be particularly important during pregnancy, which is associated with a higher frequency of oxidative reactions. Previous studies have demonstrated a relationship between reduced levels of trace elements essential for antioxidant activity in the body of pregnant women and an increased risk of developing preeclampsia [2]. Premature infants born with a low birth weight are particularly susceptible to the effects of free radicals, and this weaker antioxidant defense system may be responsible for numer- 
ous disorders often encountered and referred to as 'oxygen radical disease in neonates' [3]. Trace elements are integral parts of many compounds, acting as regulatory enzymes or hormones, and play an important role in the division and differentiation of fetal cells and their further development. It is suggested that micromineral deficiencies in pregnant women correlate with birth defects and growth disorders [4].

The appropriate concentration of trace elements in the body during pregnancy and the role of trace elements in pregnancy progression and development of the fetus is not yet fully understood. Determining reference values for concentrations of minerals in maternal serum, amniotic fluid and umbilical cord blood seems to be of particular importance. Knowing the concentration ranges of these elements in the mother and the fetus can be a significant contribution to the development of prenatal diagnosis and prevention of disorders of pregnancy.

\section{LITERATURE SEARCH STRATEGY}

Citations on the role of selected trace elements during pregnancy were searched in PubMed, Medline, Web of Science, using MeSH terms and keywords (pregnancy, trace elements, iron, zinc, copper, selenium, manganese, fetal development). Reference lists of eligible studies were manually searched.

\section{STUDY SELECTION AND DATA EXTRACTION}

Selection was performed by screening of titles and abstracts, and by full text scrutiny. The search was restricted to English language articles. Study selection was based on the following criteria using PICO. Population 1. Pregnant women with high risk of mineral deficiencies. Population 2. Pregnant women who have examined concentration of iron, zinc, copper, selenium and manganese in different test materials. In this review 708 abstracts met the search criteria, 419 of these were excluded based on inclusion and exclusion criteria. This resulted in 289 published full-text articles and abstracts. These articles and abstracts were assessed regarding inclusion and exclusion criteria. At this stage, 259 articles were excluded. Figure 1 presents the process of study selection. Data were synthesized and presented narratively.

\section{RESULTS}

Below we present the results of previous research examining the role of iron, zinc, manganese, copper and selenium on pregnancy and fetal development. The total concentration of these minerals does not exceed $0.01 \%$ of the human body, and the daily requirement is less than $100 \mathrm{mg} /$ person. These micronutrients have a significant impact on pregnancy and fetal development, despite the low concentrations. Each of them plays an important regulatory role by forming a part of a complex enzyme system. The micronutrients presented below are ordered from the highest to the lowest suggested requirement during pregnancy.

\section{Iron}

Iron plays a major role in many metabolic processes [6, 7]. It participates in redox reactions, immune processes and DNA synthesis, as well as being a substrate in the synthesis of heme, the main component of hemoglobin. Iron found in food can be present as either heme iron or nonheme iron. Large quantities of heme iron is present in red meat and offal, and is easily absorbed in this form. Non-heme iron is found primarily in food of plant origin and its bioavailability is low. Pregnant women are at a greater risk of developing iron deficiency. The demand for iron in pregnant women is $27 \mathrm{mg} /$ day [8].

During pregnancy, the body's iron requirement significantly increases, especially in the third trimester $[9,10]$. Preg-

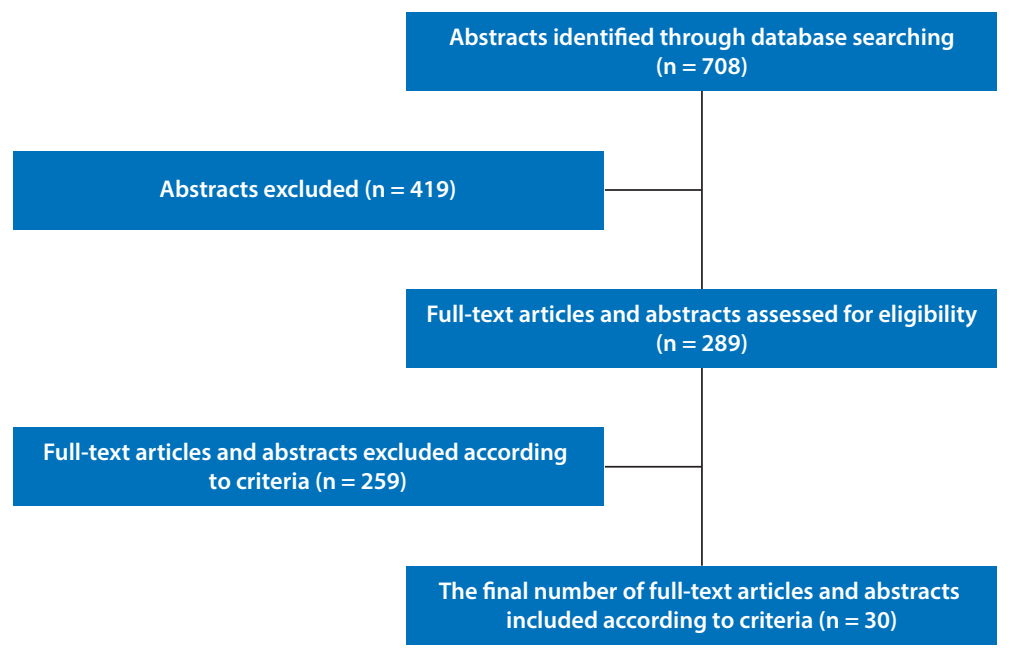

Figure 1. Selected trace elements concentrations in pregnancy and their possible role - study selection process 
nant women are therefore advised to use iron and folic acid supplements to reduce the risk of developing anemia [8]. It has been shown that the concentration of iron in the blood serum of pregnant women is less than in the cord blood [5]. However, there is a comparable concentration of iron in both maternal serum and in the colostrum during the first days after birth [5]. These results suggest that iron is transported to the mammary glands in direct proportion to its concentration in the maternal blood. High concentration of iron in the umbilical cord blood in comparison with maternal serum, may indicate active transport of iron from mother to fetus [11].

\section{Zinc}

Zinc has an important function in the human body participating in RNA, DNA and proteins synthesis, as well as playing a role in the stabilization of cell membranes and the skeletal system $[12,13]$. Zinc is a cofactor of approximately 200 enzymes, including metalloproteinases, transferases, phosphatases and oxidoreductases, and thereby contributes significantly to the immune system function and antioxidant status of the organism. Zinc is essential to the proper functioning of certain hormones, for instance insulin. However, an excessive intake of zinc can have the adverse effect of suppressing copper absorption [14-16]. The daily requirement for zinc during pregnancy ranges from 11-12 mg. Good sources of dietary zinc include whole wheat bread, buckwheat, dry legumes, cheeses and seafood, and meat from where it is best absorbed.

Epidemiological studies have shown that maternal zinc deficiency is common, especially in developing countries. According to several authors, the decrease in maternal zinc serum concentration may be due to the increase in blood volume, decrease in zinc-binding proteins concentration, hormonal changes and an increase in zinc uptake by the placenta and developing fetus [14]. The concentration of maternal zinc correlates with its concentration in the fetus [5]. Studies have shown a positive relationship between maternal serum zinc levels and zinc content in umbilical cord serum [5].

\section{Manganese}

Manganese is responsible for the normal metabolism of carbohydrates, amino acids and cholesterol. This trace element regulates the activity of numerous enzymes, which are involved in metabolic pathways and redox processes in the body $[17,18]$. The recommended daily intake of manganese for pregnant women is $2 \mathrm{mg}$. Dry seeds of legumes, whole grain cereals, buckwheat and nuts are all a good source of manganese.

\section{Copper}

During pregnancy, women requires $1 \mathrm{mg}$ of copper daily. Sunflower seeds, dried legumes, liver, nuts, cocoa and oat- meal are all rich in copper, although copper is best absorbed in the presence of animal protein. Copper is a component of superoxide dismutase, catalase and cytochrome oxidase, and as such plays an important role in oxidation reactions. In addition, by contributing to the formation of ceruloplasmin, copper plays an important role in the absorption and metabolism of iron [19-21].

Research suggests that the concentration of serum copper of pregnant women is higher than in women who are not pregnant [5]. According to Ozden et al., copper levels in the serum and hair of women 12 months after delivery was significantly lower than 2 months after giving birth. The reverse trend was observed in the infants' serum levels of copper, whereby the serum copper level was significantly higher in 12 month old infants, compared with measurements made 2 and 6 months after birth [19]. A Jariwala et al. study showed that the concentration of copper in cord blood is only $28 \%$ of that in maternal serum [5]. The authors suggest that the low levels of copper in fetal blood is due to an increase in estrogen levels during pregnancy [5].

\section{Selenium}

Selenium is a component of selenoproteins, which are crucial for proper function of the immune system, thyroid hormone synthesis and cell free radical protection, among others. Selenium is a cofactor of 5-iodothyronine deiodinase, which determines the proper function of key antioxidant enzymes deiodinase and glutathione peroxidase [22]. Pregnant women require $60 \mu \mathrm{g} /$ day of selenium. The difference between required and toxic dose of selenium is very small. A daily intake of less than $0.1 \mathrm{mg} / \mathrm{kg}$ of body weight leads to a deficiency of this microelement, while the intake of more than $1 \mathrm{mg} / \mathrm{kg}$ body weight may cause toxic effects [23, 24]. Protein-rich products are typically high in dietary selenium. These include meat, offal, fish, seafood, milk and dairy products, yeast and bread.

Results of clinical studies indicate that serum selenium concentration decreases during pregnancy [5]. The reason for this may be an increase selenium demand by the developing fetus, as well as an increased blood volume of the mother in the later stages of pregnancy [5]. Jariwala et al. noted a significantly lower selenium concentration in cord blood compared to maternal serum [5]. In addition, selenium level in colostrum was found to be significantly higher than in the maternal serum during the postpartum period [5]. The average selenium concentration in cord serum was found to be $36 \pm 10 \mu \mathrm{g} / \mathrm{L}$, which was about half that of maternal serum selenium concentration (70 $\pm 15 \mathrm{mg} / \mathrm{dL}$ ) [5]. However, the Mohammadzadeh et al. study showed a higher selenium level in cord blood compared to that of pregnant women [25]. Selenium levels in the hair of pregnant women was observed to be significantly higher than in maternal serum and in milk in the postpartum period [25]. 
Table 1. Minerals concentration in maternal serum, cord serum and amniotic fluid during pregnancy (mean \pm SD)

\begin{tabular}{|c|c|c|c|}
\hline Minerals & Maternal serum & Cord serum & Amniotic fluid \\
\hline $\mathrm{Fe}$ & $\begin{array}{c}1.132 \pm 519 \mu \mathrm{g} / \mathrm{L}[5] \\
5.10 \pm 1.48 \mu \mathrm{M} / \mathrm{L}[20]\end{array}$ & $\begin{array}{c}2.312 \pm 789 \mu \mathrm{g} / \mathrm{L}[5] \\
106 \pm 26.1 \mathrm{mg} / \mathrm{dL}[1] \\
89.8 \pm 13.2 \mathrm{mg} / \mathrm{dL}[7] \\
6 \pm 2.23 \mu \mathrm{M} / \mathrm{L}[20]\end{array}$ & - \\
\hline $\mathrm{Zn}$ & $\begin{array}{c}514 \pm 149 \mu \mathrm{g} / \mathrm{L}[5] \\
67.02 \pm 15.99 \mu \mathrm{g} / \mathrm{L}^{\mathrm{a}}[11] ; 83.59 \pm 18.46 \mu \mathrm{g} / \mathrm{L}^{\mathrm{b}}[11] \\
108.45 \mu \mathrm{g} / \mathrm{dL}^{\mathrm{c}}[2] ; 81.24 \mu \mathrm{g} / \mathrm{dL}^{\mathrm{d}}[2] \\
80.4 \pm 23 \mu \mathrm{g} / \mathrm{dL}^{\mathrm{e}}[13] ; 79.8 \pm 26 \mu \mathrm{g} / \mathrm{dL}^{\mathrm{f}}[13] \\
11.6 \pm 2.29 \mu \mathrm{M} / \mathrm{L}[20]\end{array}$ & $\begin{array}{c}819 \pm 224 \mu \mathrm{g} / \mathrm{L}[5] \\
84.1 \pm 11 \mu \mathrm{g} / \mathrm{L}[7] \\
10.6 \pm 2.35 \mu \mathrm{M} / \mathrm{L}[20] \\
85.35 \pm 16.6 \mathrm{mg} / \mathrm{dL}[1]\end{array}$ & - \\
\hline $\mathrm{Mn}$ & $\begin{array}{c}31.9 \pm 10.7 \mathrm{nM} / \mathrm{L}[20] \\
2.8 \mu \mathrm{g} / \mathrm{L}[17]\end{array}$ & $\begin{array}{c}61.3 \pm 36.3 \mathrm{nM} / \mathrm{L}[20] \\
4 \mu \mathrm{g} / \mathrm{L}[17] \\
34.4 \mu \mathrm{g} / \mathrm{L}[27]\end{array}$ & $5.78 \pm 5.01 \mu \mathrm{g} / \mathrm{L}[4]$ \\
\hline $\mathrm{Cu}$ & $\begin{array}{c}152.45 \mu \mathrm{g} / \mathrm{dL}^{\mathrm{c}}[2] ; 199.5 \mu \mathrm{g} / \mathrm{dL}^{\mathrm{d}}[2] \\
142.9 \pm 28.8 \mu \mathrm{g} / \mathrm{dL}^{\mathrm{e}}[13] ; 144.9 \pm 28.2 \mu \mathrm{g} / \mathrm{dL}^{\mathrm{f}}[13] \\
1.614 \pm 295 \mu \mathrm{g} / \mathrm{L}[5] \\
23 \pm 8.11 \mu \mathrm{M} / \mathrm{L}[20]\end{array}$ & $\begin{array}{c}301 \pm 77 \mu \mathrm{g} / \mathrm{L}[5] \\
38.6 \mu \mathrm{g} / \mathrm{dL}[22] \\
4.10 \pm 1.34 \mu \mathrm{M} / \mathrm{L}[20] \\
57.04 \pm 13.8 \mathrm{mg} / \mathrm{dL}[1]\end{array}$ & $106.7 \pm 53.6 \mu \mathrm{g} / \mathrm{L}[4]$ \\
\hline Se & $\begin{array}{c}70 \pm 15 \mu \mathrm{g} / \mathrm{L}[5] \\
704 \pm 199.7 \mathrm{nM} / \mathrm{L}[20]\end{array}$ & $\begin{array}{c}36 \pm 10 \mu \mathrm{g} / \mathrm{L}[5] \\
106.3 \pm 18.2 \mu \mathrm{g} / \mathrm{L}^{\mathrm{g}}[23] \\
101.9 \pm 15.9 \mu \mathrm{g} / \mathrm{L}^{\mathrm{h}}[23] \\
69.8 \mu \mathrm{g} / \mathrm{L}[22]\end{array}$ & - \\
\hline
\end{tabular}

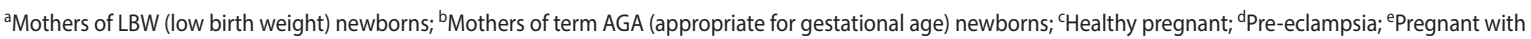
PROM (premature rupture of the membranes); ${ }^{\text {} N o ~ P R O M ; ~}{ }^{9}$ Selenium supplementation; ${ }^{\text {hP }}$ Placebo group

Table 2. Trace elements concentrations in maternal serum in pregnancy trimesters (mean \pm SD)

\begin{tabular}{|c|c|c|c|}
\hline \multirow{2}{*}{ Minerals } & \multicolumn{3}{|c|}{ Maternal serum [mg/dL] } \\
\cline { 2 - 4 } & $\mathbf{1}^{\text {st }}$ trimester & $\mathbf{2}^{\text {nd }}$ trimester & $3^{\text {rd }}$ trimester \\
\hline \multirow{2}{*}{$\mathrm{Fe}$} & $76.0 \pm 17.8[1]$ & $63.5 \pm 15.2[1]$ & $70.1 \pm 14.4[1]$ \\
$\mathrm{Zn}$ & $74.4 \pm 12.1[7]$ & $79.3 \pm 8.6[7]$ & $82.2 \pm 10.2[7]$ \\
$\mathrm{Mn}$ & $79.5 \pm 15[1]$ & $74.5 \pm 16.1[1]$ & $65.3 \pm 14.9[1]$ \\
$\mathrm{Cu}$ & $74.9 \pm 9.1[7]$ & $73.1 \pm 10.6[7]$ & $68.4 \pm 9.9[7]$ \\
$\mathrm{Se}$ & - & - & - \\
\hline
\end{tabular}

Table 1 presents results of mineral analysis of maternal serum, cord serum and amniotic fluid. However, there is a lack of information about mineral concentration in amniotic fluid. Amniotic fluid is considered a valuable marker of prenatal mineral status. Amniotic fluid is swallowed by the fetus and it has been suggested that this fluid may by an important source of minerals for fetal nutrition [4]. It was seen that there was a significant difference in the concentration of trace elements in the various compartments. The data provided by the various authors also differ significantly. Differences in the obtained results may be due to the differences between the studied pregnant women's population (parity, trimester, healthy pregnant, pregnant with PROM, pre-eclampsia, mineral supplementation). Table 2 presents trace elements concentrations in maternal serum grouped by trimesters. It was seen that the concentration of zinc decreases during pregnancy while the concentration of copper increases. In the case of iron available analysis provides conflicting results.

\section{DISCUSSION}

Most of the currently available data suggests a positive correlation between the concentration of iron in the maternal serum and the birth weight of neonates (Table 2) $[6,7]$. According to Wang et al., the impact of iron supplementation in pregnancy on the birth weight of the child depends on the concentration of hemoglobin in maternal blood before pregnancy [9]. A significant decrease in fetal iron was observed in pregnant women with anemia [10].

Bastian et al. observed a relationship between fetal and infant iron deficiency and the occurrence of developmental disorders of the nervous system [26]. Iron deficiency can result in abnormalities in brain development and cogni- 
tive impairment later on in life. Tissue iron stores depletion can lead to cellular hypoxia, which could lead to the abnormal proliferation of blood vessels in order to compensate for the oxygen deficiency in the brain. In experimental studies, iron deficiency resulted in increased angiogenesis in the brains of rats, which could have a negative impact on further development of the animal [26].

It has been suggested that low levels of maternal serum zinc may be associated with pregnancy complications and delaying growth and development of the fetus. Rahmanian et al. showed that pregnant women with and without premature rupture of the membranes had significantly lower serum zinc concentration than non-pregnant women [14]. Current data shows an association between low maternal serum zinc and sudden miscarriage, premature birth, occurrence of birth defects as well as intrauterine growth restriction and neurological disorders $[12,15]$. Research carried out among pregnant women in developed and developing countries has shown a positive correlation between zinc supplementation during pregnancy and the birth weight of the child. A significant association was shown between zinc supplementation during pregnancy and a decrease in the incidence of premature births [16].

The study by Sarwar et al. showed a significantly lower serum concentration of microminerals, including manganese, in pregnant women diagnosed with preeclampsia [17].

An extensive study by Yu et al. attempted to correlate manganese concentrations in maternal blood and umbilical cord blood with neonatal birth weight and birth length, using the ponderal index (PI) [18]. Higher concentrations of manganese were observed in umbilical cord blood than in maternal blood (Table 1). A concentration of manganese equal to or greater than $5 \mu \mathrm{g} / \mathrm{L}$ in the cord blood was correlated with a higher PI [18].

Manganese plays an important role in the correct development of the nervous system. When the concentration of manganese exceeds the recommended level, it can act as a powerful neurotoxin, affecting the function of dopaminergic neurotransmission [27]. Prolactin secretion is tonically inhibited by dopamine, and its plasma concentration can be a marker of dopaminergic system functioning. In a study involving 87 pregnant women, Tasker et al. measured manganese levels in maternal and umbilical cord serum as well as prolactin concentrations in cord serum [28]. A significant positive correlation between manganese and prolactin concentrations in cord serum was observed. These results suggest that fetal exposure to high levels of manganese can result in developmental disorders of the nervous system [28].

Deficiencies of copper during pregnancy can lead to anemia, neutropenia, abnormalities in glucose and cholesterol metabolism, and an increased susceptibility to infec- tion [19]. Copper deficiency was observed mainly among premature infants, infants recovering from diarrhea and those fed with cow's milk [19]. Several clinical studies have looked at the relationship between parity and the serum copper levels in women, and found that copper concentration was significantly lower in multiparous women compared to those who gave birth no more than twice. These studies also suggest that parity affects the maternal serum levels of microminerals, which then has an impact on the body mass index (BMI) of the mother and neonates anthropometrics [20].

Clinical studies have shown a relationship between the maternal serum copper levels and fetal development. Ugwuja et al. found that copper concentration in maternal serum negatively correlated with the newborns head circumference [20]. A negative correlation between cord blood copper levels and neonates birth weight was observed by Bermudez et al. [21]. It remains unclear whether high copper levels are a cause or a consequence of poor growth of the fetus.

Bakacak et al. showed that the copper to zinc ratio in plasma was associated with higher risk of preeclampsia in pregnancy [2]. Concentrations of both copper and zinc, as well as the copper to zinc ratio in the serum of women diagnosed with preeclampsia were significantly higher than in healthy pregnant women without preeclampsia. The authors also highlighted that the copper to zinc ratio and fetal birth weight had a significant negative correlation in women diagnosed with preeclampsia [2]. Preeclampsia is associated with an increase in lipid peroxidation levels, which may be related to elevated copper levels and increased copper to zinc ratio in maternal serum [29]. Serum triglyceride and total cholesterol levels are major risk factors for the development of metabolic disorders. Wells et al. showed a statistically significant positive correlation between serum copper and triglycerides in cord blood [23].

It is suggested that the maternal selenium concentration has an influence on neonatal anthropometric measurements. Horan et al. showed that triceps skinfold ratio was negatively associated with first trimester selenium intake [25]. Elevated levels of selenium and high total cholesterol in cord blood were correlated, but not statistically significant [23]. Other studies have shown that daily $100 \mu \mathrm{g}$ selenium supplementation during pregnancy was associated with higher triglyceride levels in cord serum [24]. On the other hand, there was no statistically significant difference in cord blood selenium levels of women who received daily selenium supplementation and the control group [24].

Available studies have shown that an increased copper to zinc ratio and decreased selenium serum level may be markers for preeclampsia risk in pregnant women [24, 30]. Wibowo et al. showed that supplementation of minerals with 
antioxidant function, had a positive effect on the reduction of preeclampsia incidence during the initial stage of pregnancy in women not diagnosed with diabetes type 1 [31].

\section{CONCLUSIONS}

Disorders of mineral status during pregnancy may be associated with impaired fetal growth, preeclampsia and anemia in both mother and child.

Further studies of trace elements concentrations in amniotic fluid, maternal serum and umbilical cord blood during pregnancy are needed to fully understand the role of iron, zinc, manganese, copper and selenium in maintaining maternal health and facilitating proper development of the fetus.

The aim of the further research should also be to determine the optimal level of minerals supplementation and their reference values in maternal serum, umbilical cord blood and amniotic fluid, which would allow for the rapid diagnosis of maternal and fetal disorders of mineral metabolism.

\section{Conflict of interest}

The authors declare no conflict of interest.

\section{REFERENCES}

1. Tabrizi FM, Pakdel FG. Serum level of some minerals during three trimesters of pregnancy in iranian women and their newborns: a longitudinal study. Indian J Clin Biochem. 2014; 29(2): 174-180, doi: 10.1007/s12291013-0336-x, indexed in Pubmed: 24757299.

2. Bakacak M, Kılınç M, Serin S, et al. Changes in copper, zinc, and malondialdehyde levels and superoxide dismutase activities in pre-eclamptic pregnancies. Med Sci Monit. 2015; 21: 2414-2420, doi: 10.12659/ /MSM.895002, indexed in Pubmed: 26280939.

3. Marseglia L, D'Angelo G, Manti S, et al. Oxidative stress-mediated aging during the fetal and perinatal periods. Oxid Med Cell Longev. 2014; 2014: 358375, doi: 10.1155/2014/358375, indexed in Pubmed: 25202436.

4. Suliburska J, Kocyłowski R, Komorowicz I, et al. Concentrations of mineral in amniotic fluid and their relations to selected maternal and fetal parameters. Biol Trace Elem Res. 2016; 172(1): 37-45, doi: 10.1007/s12011015-0557-3, indexed in Pubmed: 26547910.

5. Jariwala M, Suvarna S, Kiran Kumar G, et al. Study of the concentration of trace elements fe, $\mathrm{zn}, \mathrm{cu}$, se and their correlation in maternal serum, cord serum and colostrums. Indian J Clin Biochem. 2014; 29(2): 181-188, doi: 10.1007/s12291-013-0338-8, indexed in Pubmed: 24757300.

6. Peña-Rosas JP, De-Regil LM, Garcia-Casal MN, et al. Daily oral iron supplementation during pregnancy. Cochrane Database Syst Rev. 2015(7): CD004736, doi: 10.1002/14651858.CD004736.pub5, indexed in Pubmed: 26198451.

7. Khoushabi F, Shadan MR, Miri A, et al. Determination of maternal serum zinc, iron, calcium and magnesium during pregnancy in pregnant women and umbilical cord blood and their association with outcome of pregnancy. Mater Sociomed. 2016; 28(2): 104-107, doi: 10.5455/msm.2016.28.104-107, indexed in Pubmed: 27147914

8. World Health Organization, Guideline: Intermittent iron and folic acid supplementation in non-anaemic pregnant women, 2012. http://www. who.int/nutrition/publications/micronutrients/guidelines/guideline_intermittent_ifa_non_anaemic_pregnancy/en/.

9. Wang $\mathrm{L}, \mathrm{Mei} \mathrm{Z}$, $\mathrm{Li}$ H, et al. Modifying effects of maternal $\mathrm{Hb}$ concentration on infant birth weight in women receiving prenatal iron-containing supplements: a randomised controlled trial. Br J Nutr. 2016; 115(4): 644-649, doi: 10.1017/S0007114515004870, indexed in Pubmed: 26824731.

10. Shao J, Lou J, Rao R, et al. Maternal serum ferritin concentration is positively associated with newborn iron stores in women with low ferritin status in late pregnancy. J Nutr. 2012; 142(11): 2004-2009, doi: 10.3945/jn.112.162362, indexed in Pubmed: 23014493.
11. Kulik-Rechberger B, Kościesza A, Szponar E, Domosud J. Hepcidin and iron status in pregnant women and full-term newborns in first days of life. Ginekol Pol. 2016; 87(4): 288-292. doi: 10.17772/gp/62202.

12. Jyotsna S. Study of serum zinc in low birth weight neonates and its relation with maternal zinc. J Clin Diag Res. 2015, doi: 10.7860/jcdr/ /2015/10449.5402.

13. Maduray K, Moodley J, Soobramoney C, et al. Elemental analysis of serum and hair from pre-eclamptic South African women. J Trace Elem Med Biol. 2017; 43: 180-186, doi: 10.1016/j.jtemb.2017.03.004, indexed in Pubmed: 28325649

14. Rahmanian $M$, Jahed FS, Yousefi B, et al. Maternal serum copper and zinc levels and premature rupture of the foetal membranes. J Pak Med Assoc. 2014; 64(7): 770-774, indexed in Pubmed: 25255584.

15. Adamo AM, Oteiza PI. Zinc deficiency and neurodevelopment: the case of neurons. Biofactors. 2010; 36(2): 117-124, doi: 10.1002/biof.91, indexed in Pubmed: 20333753.

16. Ota $E$, Mori R, Middleton $P$, et al. Zinc supplementation for improving pregnancy and infant outcome. Cochrane Database Syst Rev. 2015(2): CD000230, doi: 10.1002/14651858.CD000230.pub5, indexed in Pubmed: 25927101.

17. Sarwar MdS, Ahmed S, Ullah MS, et al. Comparative study of serum zinc copper, manganese, and iron in preeclamptic pregnant women. Biol Trace Elem Res. 2013; 154(1): 14-20, doi: 10.1007/s12011-013-9721-9, indexed in Pubmed: 23749478.

18. Yu X, Cao L, Yu X. Elevated cord serum manganese level is associated with a neonatal high ponderal index. Environ Res. 2013;121: 79-83, doi: 10.1016/j.envres.2012.11.002, indexed in Pubmed: 23164521.

19. Özden TA, Gökçay G, Cantez MS, et al. Copper, zinc and iron levels in infants and their mothers during the first year of life: a prospective study. BMC Pediatr. 2015; 15: 157, doi: 10.1186/s12887-015-0474-9, indexed in Pubmed: 26467093.

20. Ugwuja El, Nnabu RC, Ezeonu PO, et al. The effect of parity on maternal body mass index, plasma mineral element status and new-born anthropometrics. Afr Health Sci. 2015; 15(3): 986-992, doi: 10.4314/ahs. v15i3.37, indexed in Pubmed: 26957991.

21. Bermúdez L, García-Vicent C, López J, et al. Assessment of ten trace elements in umbilical cord blood and maternal blood: association with birth weight. J Transl Med. 2015; 13: 291, doi: 10.1186/s12967-015-0654-2, indexed in Pubmed: 26346609.

22. Terrin G, Berni Canani R, Di Chiara M, et al. Zinc in early life: a key element in the fetus and preterm neonate. Nutrients. 2015; 7(12): 10427-10446, doi: 10.3390/nu7125542, indexed in Pubmed: 26690476.

23. Wells EM, Navas-Acien A, Apelberg BJ, et al. Association of selenium and copper with lipids in umbilical cord blood. J Dev Orig Health Dis. 2014; 5(4): 281-287, doi: 10.1017/S2040174414000233, indexed in Pubmed: 24965134.

24. Boskabadi H, Maamouri G, Rezagholizade OF, et al. Effect of prenatal selenium supplementation on cord blood selenium and lipid profile. Pediatr Neonatol. 2012; 53:334-339, doi: 10.1017/S2040174414000233.

25. Horan MK, McGowan CA, Gibney ER, et al. The association between maternal dietary micronutrient intake and neonatal anthropometry — secondary analysis from the ROLO study. Nutr J. 2015; 14: 105, doi: 10.1186/s12937-015-0095-z, indexed in Pubmed: 26445882.

26. Bastian TW, Santarriaga S, Nguyen TAn, et al. Fetal and neonatal iron deficiency but not copper deficiency increases vascular complexity in the developing rat brain. Nutr Neurosci. 2015; 18(8): 365-375, doi: 10.1179/1476830515Y.0000000037, indexed in Pubmed: 26177275.

27. Yu X, Chen L, Wang C, et al. The role of cord blood BDNF in infant cognitive impairment induced by low-level prenatal manganese exposure: LW birth cohort, China. Chemosphere. 2016; 163: 446-451, doi: 10.1016/j. chemosphere.2016.07.095, indexed in Pubmed: 27565312.

28. Takser L, Mergler D, de Grosbois S, et al. Blood manganese content at birth and cord serum prolactin levels. Neurotoxicol Teratol. 2004; 26(6): 811-815, doi: 10.1016/j.ntt.2004.07.001, indexed in Pubmed: 15451044.

29. Atamer $Y$, Koçyigit $Y$, Yokus B, et al. Lipid peroxidation, antioxidant defense, status of trace metals and leptin levels in preeclampsia. Eur J Obstet Gynecol Reprod Biol. 2005; 119(1): 60-66, doi: 10.1016/j.ejogrb.2004.06.033, indexed in Pubmed: 15734086.

30. Haque MdM, Moghal MdM, Sarwar MdS, et al. Low serum selenium concentration is associated with preeclampsia in pregnant women from Bangladesh. J Trace Elem Med Biol. 2016; 33: 21-25, doi: 10.1016/j. jtemb.2015.08.002, indexed in Pubmed: 26653739.

31. Wibowo N, Purwosunu Y, Sekizawa A, et al. Antioxidant supplementation in pregnant women with low antioxidant status. J Obstet Gynaecol Res. 2012; 38(9): 1152-1161, doi: 10.1111/j.1447-0756.2012.01855.x, indexed in Pubmed: 22563751. 